\title{
Review
}

\section{Astroglia in dementia and Alzheimer's disease}

\author{
JJ Rodríguez ${ }^{\star, 1,2}$, M Olabarria ${ }^{1}$, A Chvatal ${ }^{2}$ and A Verkhratsky ${ }^{*, 1,2}$
}

\begin{abstract}
Astrocytes, the most numerous cells in the brain, weave the canvas of the grey matter and act as the main element of the homoeostatic system of the brain. They shape the microarchitecture of the brain, form neuronal-glial-vascular units, regulate the blood-brain barrier, control microenvirionment of the central nervous system and defend nervous system against multitude of insults. Here, we overview the pathological potential of astroglia in various forms of dementias, and hypothesise that both atrophy of astroglia and reactive hypertrophic astrogliosis may develop in parallel during neurodegenerative processes resulting in dementia. We also show that in the transgenic model of Alzheimer's disease, reactive hypertrophic astrocytes surround the neuritic plaques, whereas throughout the brain parenchyma astroglial cells undergo atrophy. Astroglial atrophy may account for early changes in synaptic plasticity and cognitive impairments, which develop before gross neurodegenerative alterations.

Cell Death and Differentiation (2009) 16, 378-385; doi:10.1038/cdd.2008.172; published online 5 December 2008
\end{abstract}

Astrocytes, for the first time visualised by Otto Deiters ${ }^{1}$ and Christianised by Michael von Lenhossek ${ }^{2}$ (for historical overview, see also references $\left.{ }^{3,4}\right)$, are the main type of glia in the central nervous system (CNS). The astrocytes, which dwell in both grey and white matter, are the main element of brain homoeostatic system, being responsible for all aspects of metabolic support, nutrition, control of ion and neurotransmitter environment, regulation of brain-blood barrier and defence of the CNS., ${ }^{5,6}$ In addition, astroglial cells are endowed with numerous signalling cascades, which include a wide array of plasmalemmal neurotransmitter receptors and intracellular second messenger pathways. ${ }^{7-10}$ These pathways in combination with trans-cellular communication routes represented by gap junctions ${ }^{11,12}$ and regulated gliotransmitter release ${ }^{13}$ support information processing within glial networks, the mechanisms and functional relevance of which remains essentially enigmatic.

The main type of astroglia in the grey matter, the protoplasmic astrocytes, are characterised by complex morphology with elaborated processes, which cover neuronal membranes, residing within the astrocytic territories; the latter being defined by the arborisation of a single astrocyte. Importantly, a single-astroglial microanatomical domain is essentially free from the processes of other astrocytes, giving the grey matter in the brain and in the spinal cord a regular parcellating structure. ${ }^{14} \mathrm{~A}$ single astrocyte in the rodent brain has a volume $\sim 66000 \mu \mathrm{m}^{3}$, and the membrane of this astrocyte covers around 140000 synapses lying within the astroglial domain; ${ }^{15}$ human astrocytes are considerably larger and more complex and their processes wrap up to 2 millions of synapses. ${ }^{16}$ Protoplasmic astrocytes send processes to neighbouring blood vessels, where these processes form endfeet plastering the capillary wall and participating in formation of blood-brain barrier. As a result, astroglial cells integrate neurones and blood vessels into relatively independent neuronal-glial-vascular units. Astroglial endfeet are capable of releasing vasoactive substances that control local blood flow and coordinate the latter with neuronal activity. ${ }^{17-19}$

Individual astroglial domains are further integrated into an internally continuous superstructure, because the peripheral processes of astroglial cells are coupled through gap junctions, which form a specific pathway for intercellular communications binding astroglia into a functional syncytium. This coupling most likely has anatomical specificity, providing for specific organisation of glial networks: for example, in somato-sensory cortex astroglial coupling is restricted to the

${ }^{1}$ Faculty of Life Sciences, The University of Manchester, Manchester, UK and ${ }^{2}$ Institute of Experimental Medicine, ASCR, Videnska 1083,14220 Prague 4, Czech Republic

${ }^{*}$ Corresponding authors: JJ Rodríguez, Faculty of Life Sciences, The University of Manchester, 1.124 Stopford Building, Oxford Road, Manchester M13 9PT, UK. E-mail: Jose.Rodriguez-arellano@manchester.ac.uk; Tel: + 44161275 7324; Fax: + 441612753938

or A Verkhratsky, Faculty of Life Sciences, The University of Manchester, 1.124 Stopford Building, Oxford Road, Manchester M13 9PT, UK.

E-mail: alex.verkhratsky@manchester.ac.uk; Tel: + 44161275 5414; Fax: + 441612753938

Keywords: astrocyte; Glia/Alzheimer's disease; dementia

Abbreviations: 3xTg-AD, triple-transgenic mice model of AD; AD, Alzheimer's disease; APP, Amyloid precursor protein; APP/ApoE-KO, Double-transgenic mice overexpressing a human mutated form of APP (APP ${ }^{\mathrm{V} 717 \mathrm{~F}}$ ) in combination with ApoE gene knockout; APP ${ }_{751 S L}$, Single-transgenic mice expressing APP mutation APP $\mathrm{Ser}^{751}$ to Leu; $\mathrm{APP}_{751 \mathrm{LL}} / \mathrm{PS}_{\mathrm{M} 146 \mathrm{~L}}$, Double-transgenic mice expressing $\mathrm{APP}_{751 \mathrm{SL}}$ and $\mathrm{PS}_{\mathrm{M} 146 \mathrm{~L}} ; \mathrm{APP}_{\mathrm{SWE}}$, Single-transgenic mice expressing the 'Swedish' APP doublepoint mutations Lys $^{670}$ to Asn and Met ${ }^{671}$ to Leu; APP SWE $_{\text {PSS1 }}$ dE9, Double-transgenic mice expressing APPswe and PS1 $1_{\mathrm{dEg}} ; \mathrm{CNS}$, central nervous system; FAD, Familial form of Alzheimer's disease; GFAP, glial fibrillary acidic protein; HAD, HIV-1-associated dementia; nAChR, nicotinic cholinoreceptor; nbm, nucleus basalis magnocellularis; PDAPP, Single-transgenic mice expressing the 'Swedish' and 'Indiana' APP mutations Asp ${ }^{664}$ to Ala (PDAPP(D664A); PS1, Preseniline 1; PS1 dE9, Single-transgenic mice (line S-9) expressing human PS1 carrying the exon 9-deleted variant associated with FAD; PS1 ${ }_{\mathrm{M} 146 \mathrm{~L}}$, Single-transgenic mice expressing PS1 mutation Met ${ }^{146}$ to Leu; Tau ${ }_{\mathrm{P} 301 \mathrm{~L}}$, Single-transgenic mice expressing the Pro ${ }^{301}$ to Leu tau mutation (P301L)

Received 25.7.08; revised 23.10.08; accepted 24.10.08; Edited by N Bazan; published online 05.12.08 
barrel superstructure. ${ }^{20}$ Gap junctions provide for intercellular diffusion of variety of substances, including ions, second messengers and metabolites such as glucose and ATP. ${ }^{21-23}$ This intercellular route underlies long-distance communications within glial networks; one of the examples of such communication is represented by glial calcium waves; ${ }^{21,24,25}$ yet propagating waves of other molecules can also be relevant for intercellular signalling and information processing. $^{26}$

Functional integration between neuronal and glial networks is accomplished mainly through chemical transmission, although there are incidental appearances of neuronal-glial gap junctions. ${ }^{27,28}$ Synaptic transmission in neuronal-glial circuitry occurs either at the level of tripartite synapse (when perisynaptic astroglial processes are directly exposed to neurotransmitter released from the neuronal terminals, ${ }^{29,30}$ ) or in neuronal-glial synapses. ${ }^{31,32}$ The mechanisms of glia to neurones signalling are more complex; at least in part they may involve the exocytotic release of gliotransmitters. ${ }^{13}$

\section{Astroglia in neurological diseases}

Progression and outcome of neurological diseases are determined by the balance between destruction, neuroprotection and regeneration. In this context, glial cells are invariably involved in every kind of neuropathology, which, to a very large extent, is shaped by glial performance. ${ }^{6,33}$ Astrocytes, in accordance with their homoeostatic function, are deeply involved in neural diseases. Astroglia forms the first line of brain defence by controlling the volume and composition of extracellular space. Astrocytes buffer an excess of extracellular $\mathrm{K}^{+}$, thus maintaining neuronal excitability, ${ }^{34}$ control extracellular levels of glutamate ${ }^{35,36}$ thereby limiting the intrinsic excitotoxicity of the latter, regulate fluid movements and provide the main antioxidant system in the brain. ${ }^{37}$ At the very same time astroglial cells can contribute to neuronal damage, when, for example, severe insults compromise astrocyte metabolism, which leads to a depolarisation and reversal of glutamate uptake system, the latter underlying the release of additional glutamate, thus exacerbating the brain damage. $^{6}$

Acute and chronic brain insults trigger a specific glial reaction, generally known as reactive astrogliosis, represented by a complex morphofunctional remodelling of astrocytes. ${ }^{38}$ Reactive astrogliosis is a defensive brain reaction which is aimed at (i) isolation of the damaged area from the rest of the CNS tissue, (ii) reconstruction of the blood-brain barrier and (iii) facilitation of the remodelling of brain circuits in areas surrounding the lesioned region. ${ }^{39,40}$ As a result, astrogliosis comes in different guises. Astrocytes surrounding the lesion undergo a robust hypertrophy and proliferation, which ultimately ends up in complete substitution of previously existing tissue architecture with a permanent glial scar; this process is called anisomorphic (i.e., changing the morphology) astrogliosis. In astrocytes more distal to the damage, the reactive changes are much milder and, although astroglial cells modify their appearance and undergo multiple biochemical and immunological changes, they do not distort the normal architecture of CNS tissue, but rather permit growth of neurites and synaptogenesis, thus facilitating the remodelling of neuronal networks. This type of astrocyte reaction is defined as isomorphic (i.e., preserving morphology) astrogliosis.

\section{Astroglia and dementia}

Dementia is the ultimate scourge of mankind, being generally absent in every other animal species; and as such it may be considered as the most appalling and horrible disease, because it effectively robs human beings from their intelligence and turns them into helpless entities. The causes of dementia are many, ranging from traumatic injuries (mechanical, chemical or as a result of irradiation) and viral infections, which may predispose to dementia-related chronic neurodegenerative conditions, to the intrinsic neurodegenerative processes associated with genetic factors, predispositions and other yet unknown reasons. The pathological role of astroglia in dementiae begun to be explored only very recently; however, some generalisations can already be drawn.

First and foremost, both astrogliosis and astroglial dystrophy are manifest in different types of dementia; furthermore, both these processes may develop in parallel depending on the disease form and/or stage. The frontotemporal dementias (the clinical term covering several types of sporadic nonAlzheimer cognitive disruptions, which include e.g., Pick's disease and frontotemporal lobar degeneration), is, for example, associated with a very early and profound apoptotic death and dystrophy of astrocytes. ${ }^{41}$ The degree of astroglial loss directly correlates with the severity of dementia. Conversely, other study, using postmortem tissues from 21 frontotemporal dementia cases, found prominent astrogliosis in the frontal and temporal cortices at the very early stages of the disease, with astrocyte densities increasing by 4-5 times of the control. ${ }^{42}$

Astrogliosis also assumes the leading pathological role in thalamic dementia (the rather rare form of specific dementia of unknown aetiology). Numerous alterations of protoplasmic astrocytes, manifested by highly localised proliferation of perivascular and peryneuronal astroglial processes, believed to be a primary pathological change, which can produce dementia even without severe neuronal loss. ${ }^{43}$ Similarly, in HIV-1-associated dementia (HAD) significant astroglial hypertrophy and increase in GFAP (glial fibrillary acidic protein) expression is observed in entorhinal cortex and hippocampus. ${ }^{44}$ Furthermore, there are indications that HIV-1 infected reactive astrocytes, together with activated microglial cells, may constitute a primary cause of neuronal damage, through the release of various inflammatory and death factors. ${ }^{45,46} \mathrm{At}$ the same time, however, HAD also leads to a prominent apoptotic death of astrocytes especially in the patients with rapidly progressing cognitive deficits. ${ }^{47}$

\section{Astroglia and Alzheimer's disease}

Alzheimer's disease (AD), existing in both genetic (familial AD or FAD) and sporadic forms, ${ }^{48}$ is characterised by severe neurodegeneration associated with an occurrence of specific histopathological markers represented by focal extracellular deposits of fibrillar $\beta$-amyloid (also called neuritic plaques) in 
brain parenchima and in the wall of blood vessels and intraneuronal accumulation of neurofibrillary tangles composed from abnormal hyperphosphorylated tau filaments. The progression of $A D$ is rather stereotypic with initial neurodegenerative events appearing in the transentorhinal cortex, which afterwards spread to the entorhinal cortex and hippocampus. Subsequently, the spreading wave of neurodegeneration swallows the rest of the temporal, frontal and parietal lobes. ${ }^{49,50}$ At the advanced stage of the AD, the grey matter undergoes severe damage manifested by a profound loss of neurones and synaptic contacts.

The pathological potential of glial cells in progression of dementia (as well as in other types of brain pathology) was originally suggested by Alois Alzheimer himself in $1910 .^{51}$ Many studies of the AD-related pathological potential of astroglia have focused on the investigations of the effects of $\beta$-amyloid on astrocytes. The treatment of cultured glial cells with aggregated $\beta$-amyloid or with amyloid plaques isolated from human AD brains triggered reactive astrogliosis. ${ }^{52}$ In mixed astroglial-neuronal cultures $\beta$-amyloid peptide (A $\beta$ 1-42) and its toxic fragment (A $\beta$ 25-35) provoked sporadic increases and/or oscillations in cytosolic calcium $\left[\mathrm{Ca}^{2+}\right]_{\mathrm{i}}$, which lasted for many hours. ${ }^{53}$ These $\left[\mathrm{Ca}^{2+}\right]_{\mathrm{i}}$ responses were observed solely in astrocytes and never in neurones and were generated by $\mathrm{Ca}^{2+}$ influx from extracellular space, most likely through transmembrane channels formed by $\mathrm{A} \beta$ proteins. Importantly, astroglial $\left[\mathrm{Ca}^{2+}\right]_{i}$ fluctuations were somehow linked to neuronal death, which occurred $24 \mathrm{~h}$ after $\mathrm{A} \beta$ treatment; inhibition of $\mathrm{Ca}^{2+}$ influx had a clear neuroprotective effect. ${ }^{53}$

In the AD human tissue the main astroglial reaction found hitherto is represented by prominent astrogliosis, mostly observed in the cells surrounding amyloid plaques. ${ }^{54} \mathrm{Im}$ portantly, activated astrocytes are capable of accumulating large amounts of $\mathrm{A} \beta ;^{55}$ the later being taken up by astrocytes in association with neuronal debris. In addition, reactive astrocytes seem to accumulate large amounts of neuronal subtype of nicotinic cholinoreceptor ( $\alpha 7 \mathrm{nAChRs})$, which is known to have an exceptionally high affinity to $\beta$-amyloid. Astroglial $\beta$-amyloid deposits are clearly associated with plaques, as astrocytes positioned away from the plaques show no $\beta$-amyloid burden. ${ }^{54,55}$ Processes of activated astrocytes were also reported to participate in plaques formation. ${ }^{54,55}$

At the very same time astroglial changes during $A D$ progression remain virtually unexplored. The main reason for this is purely experimental as for many years the suitable animal models for AD were absent.

\section{Animal models of AD}

Alzheimer's disease, as every other dementia, is a sole prerogative of humans; no animal suffers from AD. ${ }^{56}$ Hence, substantial efforts were invested in producing relevant animal models of $A D$ (for a comprehensive review of literature, see references ${ }^{57,58}$ ). Initial models of $A D$ were simply normal aged animals, ${ }^{59,60}$ which showed cholinergic involution associated (in monkeys) with $\beta$-amyloid deposition. ${ }^{61}$ As the $A D$ is manifested by a loss of cholinergic neurones, ${ }^{62}$ several cholinergic models of the disease were created. Among
Table 1 Summary of the transgenic $A D$ animal models and the observed neuropathology

\begin{tabular}{|c|c|c|}
\hline $\begin{array}{l}\text { Transgenic } \\
\text { mouse model }\end{array}$ & Neuropathology & Reference \\
\hline APP $_{S W E}$ & Plaques & 68 \\
\hline PDAPP & Plaques & 69 \\
\hline $\mathrm{APP}_{751 \mathrm{SL}}$ & Plaques & 70 \\
\hline $\mathrm{PS}_{\mathrm{M} 146 \mathrm{~L}}$ & Plaques & 70 \\
\hline $\mathrm{APP}_{\mathrm{SWE}} / \mathrm{PS} 1_{\mathrm{dE} 9}$ & Plaques & 71 \\
\hline APP/apoE-ko & Plaques & 72 \\
\hline TgCRND8 APP $_{95}$ & Plaques & 73 \\
\hline $\mathrm{APP}_{751 \mathrm{SL}} / \mathrm{PS} 1_{\mathrm{M} 146 \mathrm{~L}}$ & Plaques & 70 \\
\hline THY-Tau22 & Tangles & 74 \\
\hline $\mathrm{Tau}_{\mathrm{P} 301 \mathrm{~L}}$ & Tangles & 68 \\
\hline $3 x T g-A D$ & Plaques and tangles & 75 \\
\hline
\end{tabular}

these, the most relevant were the rodent models with lesions in the nucleus basalis magnocellularis $(\mathrm{nbm})$ that is the equivalent of the nucleus of Meynert in humans. ${ }^{56,63,64}$ These models offered the possibility to investigate the differences in structure, function and behaviour of the cholinergic systems in young and aged animals. ${ }^{63,64}$ The majority of these models, however, were created by using non-selective excitotoxic toxins such as NMDA, ibotenic acid, quisqualic acid and certain alkaloid substances. ${ }^{56}$ More refined lesion models used more selective and specific toxins that affected only cholinergic neurones in the relevant areas, such as septum, $\mathrm{nbm}$ and the diagonal band of Broca, but preserved non-cholinergic neurones. ${ }^{56,65}$ These models were produced by using AF64A cholinotoxin, which binds to the high affinity choline uptake system, and 192 IgG-saporin that binds selectively and irreversibly to low affinity nerve growth factor receptor interrupting cholinergic neuronal protein synthesis. Both these interventions lead to selective impairment and death of cholinergic neurones.

None of the models mentioned above, however, mimicked the histopathology (plaques and tangles) and progression of AD. Therefore several experimental transgenic animals that replicate various neuropathological features of $A D$ have been developed (see Table 1 and reference ${ }^{58}$ ). Initially, simple transgenic models harbouring single-mutated $\beta$-amyloidrelated proteins (amyloid precursor protein (APP) or presenilines, PS) or mutated tau were created. The very first APP transgenic animal showing an AD-like pathology was developed in 1995 by Games et al. ${ }^{66}$ This model was called PDAPP (single-transgenic mice expressing the 'Swedish' and 'Indiana' APP mutations Asp ${ }^{664}$ to Ala (PDAPP(D664A)) and showed many pathological features of $A D$, including extracellular $\beta$-amyloid deposits, neuritic dystrophy, astrogliosis and memory impairments, yet the latter did not correlate with the degree of $\beta$-amyloid deposition. ${ }^{58,66}$ Subsequently, Hsiao et al. ${ }^{67}$ developed the transgenic mice carrying APP mutation (Tg2576 mice) using a prion protein vector. These animals had abundant $A \beta$ plaques as well as a memory and learning impairment from 9 months of age. Subsequently, the double-APP mutation, resulting the APP23 mouse was created. This model showed a $14 \%$ loss of hippocampal CA1 pyramidal neurons.

Mutations in PS proteins account for the majority of cases of FAD. ${ }^{58}$ To address the role of genetic risk factors in APP 
a
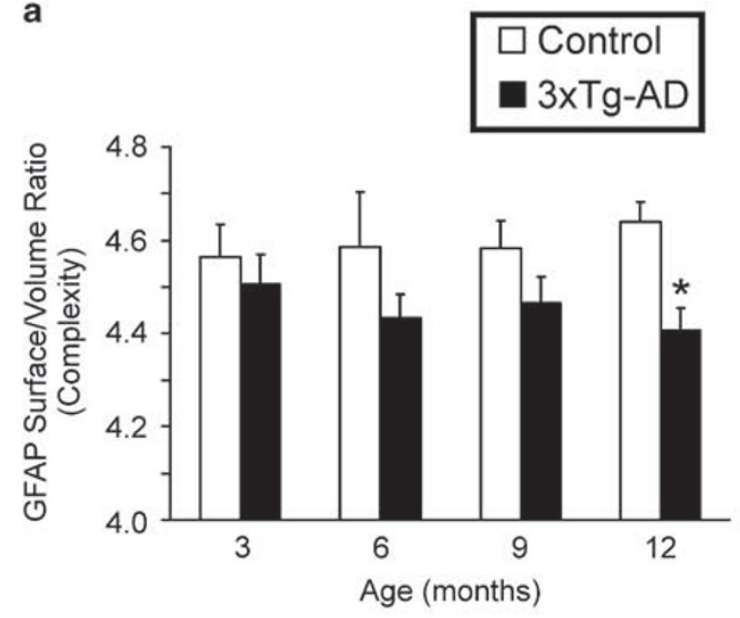

Control

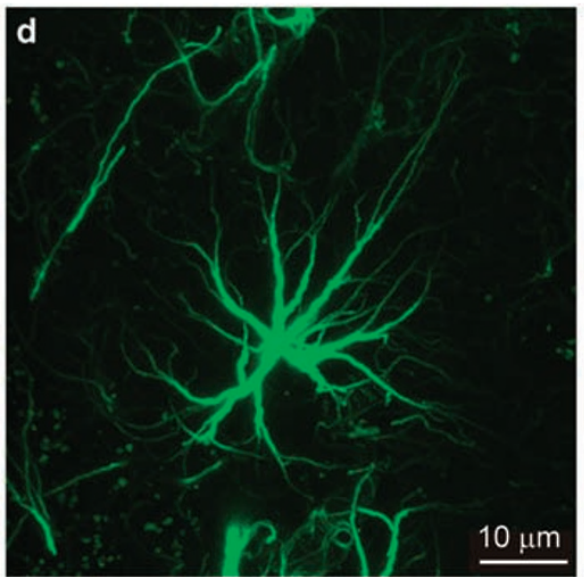

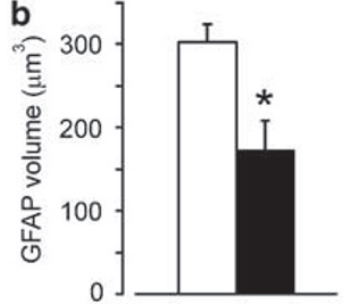

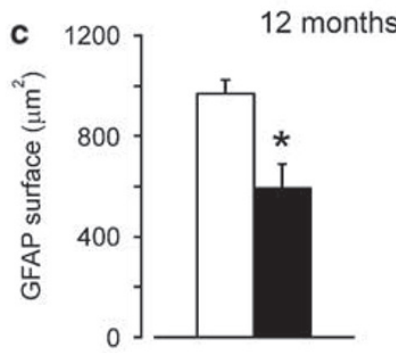

$3 \times \operatorname{Tg}-\mathrm{AD}$

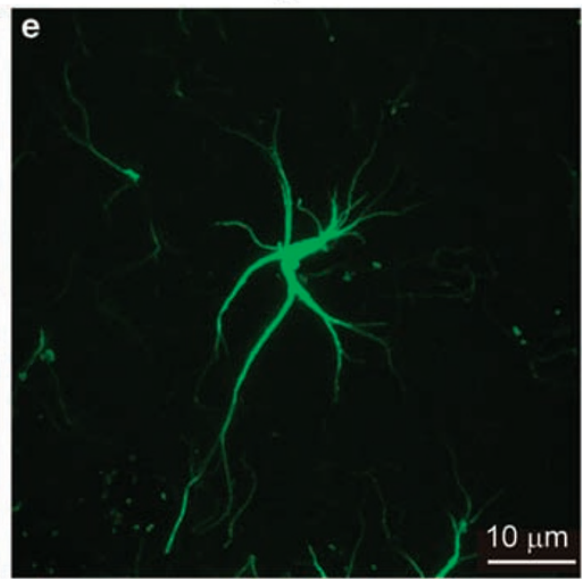

Figure 1 Bar graphs showing the complexity (a) of glial cytoskeleton by measuring the GFAP area coverage versus volume ratio of within the molecular layer of the dorsal dentate gyrus of both control and 3xTg-AD mice at different ages. (b and $\mathbf{c}$ ) Bar graphs showing the coverage area (b) and volume (c) of GFAP at 12 months of age in control and 3xTg-AD mice; * $P<0.05$ compared with age matching controls. (d and e) Fluorescence photomicrographs showing GFAP-positive cells in control (d) and 3xTg-AD mice (e) at 12 months of age. There is an evident decrease in arborisation, surface area and volume in 3xTg-AD mice when compared with matching controls. All animal procedures were performed according to the Animal Scientific Procedures Act of 1986 under the licence from the United Kingdom Home Office. The animals group were housed and kept on daily $12 \mathrm{~h} \mathrm{light-dark}$ cycles dark schedule. All mice were given ad libitum access to food and water

processing and memory, double transgenic have been created. Co-expression of $P S 1_{\mathrm{dE}}$ with $\mathrm{APP}$ resulted in a viable model that showed accelerated $\mathrm{A} \beta$ deposition and memory deficits without tangle formation. ${ }^{71}$ Expression of mutant APP on an ApoE knockout background did not affect the age of onset of $\mathrm{A} \beta$ plaques but instead of fibrillar $\mathrm{A} \beta$ mature plaques, only diffuse plaques were formed, suggesting that $A p o E$ affects fibrillogenesis and/or clearance of $A \beta{ }^{76}$

The pathological tau animals were developed in parallel, the first model being created in $1995 ;^{77}$ these transgenic animals showed somatodendritic localisation of hyperphosphorlation of tau, but have not developed neurofibrillary tangle pathology (NFT). After identification of the pathogenic mutations of tau in FTDP-17, different transgenic models with clear neuronal NFT were produced. ${ }^{57,58}$ The Tau ${ }_{\mathrm{P} 301 \mathrm{~L}}$ (single-transgenic mice expressing the Pro ${ }^{301}$ to Leu tau mutation (P301L)) mutation is the most common associated mutation linked with
FTDP-17. ${ }^{78}$ Transgenic mice overexpressing Tau $\mathrm{P}_{\mathrm{P} 301 \mathrm{~L}}$ exhibit neurofibrillary tangles without $A \beta$ pathology and/or neuronal loss, except for the spinal cord (Table $1 ;{ }^{58,78}$ ).

The triple-transgenic (3xTg-AD) AD animal model. One of the most advanced $A D$ animal models is represented by the triple-transgenic mice developed in 2003 by Salvatore Oddo and Frank LaFerla. These animals (the 3xTg-AD mouse model) harbour the mutant genes for amyloid precursor protein $\left(\mathrm{APP}_{\mathrm{Swe}}\right)$, for presenilin $1 \mathrm{PS} 1_{\mathrm{M} 146 \mathrm{~V}}$ and for tau P301L. $^{75,79}$ These mice are recognised as relevant $A D$ model because they show temporal- and region-specific $A \beta$ and tau pathology, which closely resembles that seen in the human $A D$ brain. As well as progressively developing plaques and tangles, the $3 \times T g-A D$ animals also show clear functional and cognitive impairments including LTP, spatial memory and long-term memory deficits. These all are 


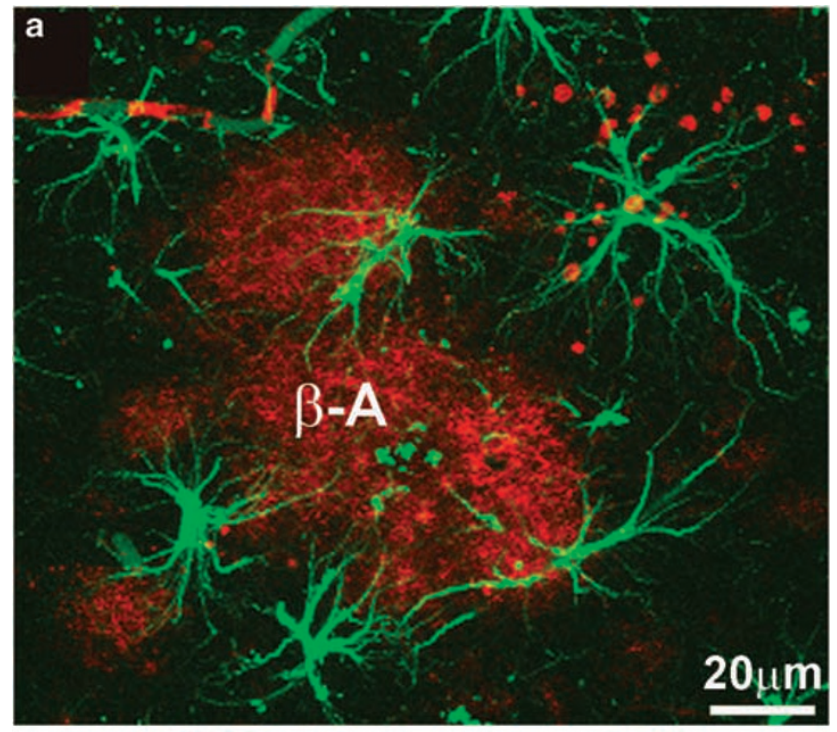

immunohistochemical labelling. ${ }^{82}$ For this labelling, we used the antibodies to GFAP an astroglia cytoskeleton-specific protein which expression varies between different brain regions and is upregulated upon reactive astrogliosis, or combined GFAP immunostaining with antibodies against $\beta$-amyloid. Morphology of GFAP-positive astrolglial profiles was reconstructed from series of optical confocal planes taken from $50 \mu \mathrm{m}$ thick fixed brain slices. After the reconstruction of individual astrocytes the following parameters were determined: surface area, volume and cellular complexity (area versus volume; for the detailed description of imaging/analysis techniques, see references ${ }^{83,84}$ ).

Morphological characterisation of GFAP-positive astroglial cells was performed on animals of different ages, from 3 to 12 months. To our surprise we found consistent reduction in the GFAP expression (determined as surface and volume of GFAP-positive profiles), which progressed with age. In very young animals ( 3 months old), which did not have any signs of AD pathology, astroglial morphology was already somewhat altered. There was a slight reduction in astrocyte complexity (by $1.29 \%$; Figure 1a) that was directly associated with a decrease in the number of processes and overall decrease in both surface $(12.62 \%)$ and volume (14.25\%; data not shown) of GFAP-labelled structures. Similar reduction in GFAPlabelled profiles was observed at all ages, although this decrease becomes significant only at 12 months of age. In 12 -month-old animals the complexity was reduced by $5.04 \%$ $(P=0.0105$; Figure 1a, $\mathrm{d}$ and $\mathrm{e})$, whereas GFAP-positive surface decreased by $38.99 \%$ and volume by $42.93 \%$ $(P=0.0211,0.0292$, respectively; Figure 1$)$. On a cellular level, this decrease in complexity was reflected by reduced number of main processes and their arborisation (Figure 1c).

Incidentally, the same decrease in astrocytes complexity was found in the postmortem brains of dementia patients. In this study, ${ }^{85}$ astroglial cells from neocortical area 11 were Golgi impregnated and their complexity was characterised by a fractal dimension. Astrocytes from adult and healthy aged participants had similar complexity, whereas astrocytes from patients with dementia showed significant decrease in fractal dimension, thus indicating the decreased complexity. Furthermore, the volume of the brain parenchima occupied by the processes of single astrocyte was smaller in demented brains.

At the very same time confocal images revealed that the manifest in an age-related manner; most importantly functional deficits precede the appearance of histological markers. ${ }^{75,79}$ Cognitive deficits in the $3 \times T$ Tg-AD model correlate with the accumulation of intraneuronal $A \beta{ }^{80,81}$

It has to be noted, however, that all animal models of $A D$ developed so far have some limitations, the most serious one being the absence of significant neuronal loss. This may reflect some intrinsic differences between human and animal brain, shorter lifespan of experimental animals or influence of other yet unknown factors. At the same time absence of neuronal loss in animals undergoing severe amyloidosis may also question the toxic potential of neuritic plaques.

Glial atrophy and astrogliosis in transgenic $A D$ animals. We characterised morphology of astroglia in the hippocampus of male 3xTG-AD mice using single and dual specific population of astrocytes surrounding amyloid plaques display the typical reactive characteristics (Figure 2), showing thick processes and enlarged cell bodies. Some of these astrocytes closely associated with amyloid plaques showed $\beta$-amyloid accumulation, as revealed by specific antibodies (Figure $2 \mathrm{~b}$ ). Conversely, astrocytes positioned away from the plaques did not show $\beta$-amyloid burden, which is consistent with previous observations. ${ }^{54,55}$

The 3xTg-AD animals show other changes that could be associated with glial malfunction. For example, we observed a transient increase in the number of asymmetric excitatory synapses in AD mice at 2 months of age, which subsequently dropped to control levels at 6-9 months. Nonetheless, this increase in excitatory synaptic contacts re-emerged again at 12 months of age when the brain parenchyma was infested with plaques, and neurones showed tangles. ${ }^{86}$ In addition, we 
Astroglial atrophy in the plaque-free parenchima

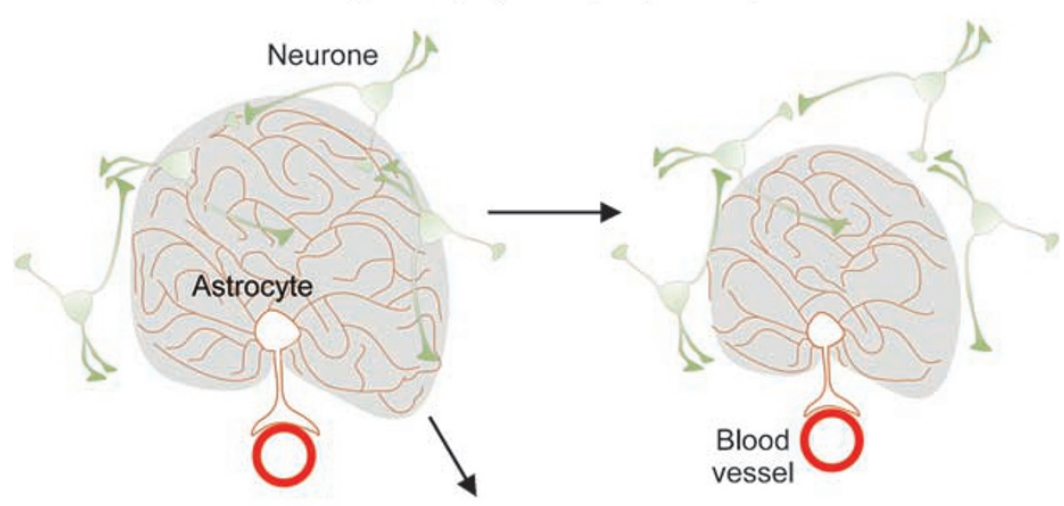

Reactive astrocytes surround neuritic plaques

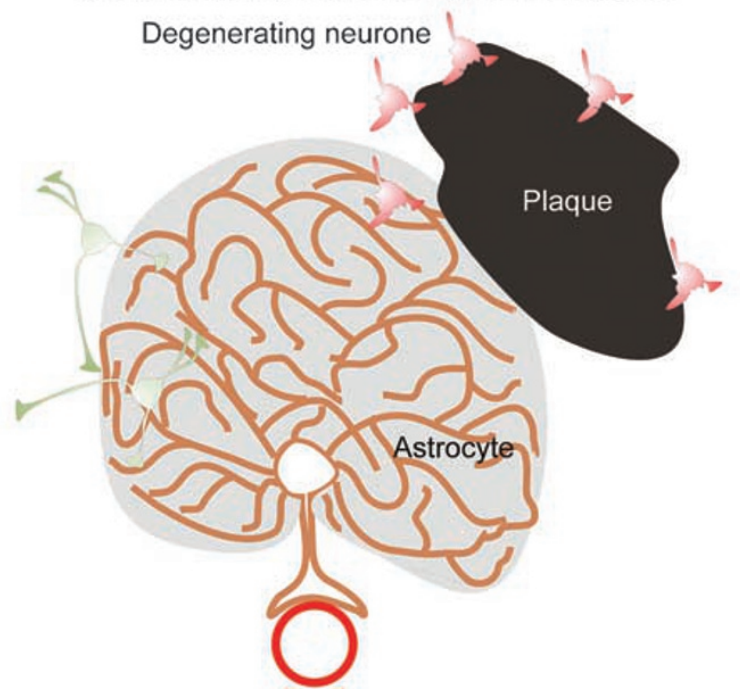

Figure 3 Astroglial hypothesis of Alzheimer's disease

also found significant decrease in the neurogenic capacity of $3 x-T g-A D$ mice at 12 months of age, ${ }^{87}$ which may reflect degenerative changes in 'stem-cell'-like astrocytes.

\section{Astroglial theory of AD?}

The pivotal role of astroglia in various types of brain pathology is widely accepted. ${ }^{6,88,89}$ Nevertheless, the pathological potential of astrocytes in human dementias remains virtually unexplored. From the scarce data available in the literature, we may conclude that astrocytic reactions in various types of dementia can be manifold, ranging from proliferation and astrogliosis to apoptosis and dystrophy.

In $A D$, these two reactions develop in parallel and may represent the underlying mechanism for loss in synaptic connectivity and plasticity, which in turn determine cognitive deficits. The reaction of astrocytes to the $A D$ progression is spatially distinct (Figure 3): astroglial cells surrounding the plaques undergo gliosis, whereas astrocytes distant from the amyloid deposits develop atrophy. The first signs of this atrophy appear early in the genetic form of AD pathology in mice; and these signs precede the formation of both plaques and tangles. It is then conceivable to speculate that dystrophic astrocytes fail to provide adequate support for synaptic contacts, which may lead to their remodelling (e.g., distorted balance between excitatory and inhibitory synapses), with ensuing disruption of neuronal circuitry - and indeed the synaptic loss is observed in early stages of $A D$ when brain parenchyma remains relatively free from neuritic plaques. ${ }^{90,91}$ Furthermore, reduced astroglial coverage may significantly affect extracellular brain homoeostasis. In particular, dystrophic astrocytes may have reduced ability for glutamate uptake, thus increasing the overall brain vulnerability to glutamate excitotoxicity. In contrast, the reactive astroglial cells may serve another function - the function of neuronal killers. Indeed, the main pillar of $\beta$-amyloid hypothesis of $A D$, the toxicity of the neuritic plaques has been considerably shaken by experiments on transgenic animals. The latter, despite acquiring a heavy burden of amyloid plaques, show very little (if any) neuronal death. ${ }^{58}$ This discrepancy is fundamental, as massive neuronal death assumes the main role in the development of severe dementia in humans. Naturally, the absence of neuronal extinction in the animal model can be explained by a variety of reasons, yet it may also hint that alternative mechanisms of the neurodegenerative process are in operation. These mechanisms could be 
associated with both astroglial atrophy (reduced glutamate uptake with increased glutamate excitotoxicity) and astrogliosis, as reactive astrocytes and activated microglia may secrete numerous death-promoting molecules.

The AD, as well as other types of dementia, are complex processes which engulf all cellular elements in the brain. Can astrocytes assume the central stage in these pathologies? This question requires further detailed and insightful investigation.

Acknowledgements. We thank the National Institute of Health, INTAS, Alzheimer Research Trust UK and European commission for the grant support. AC research was supported by the Grant Agency of the Czech Republic (nos. 305/06/ $1316,305 / 06 / 1464,305 / 08 / 1384$ and 309/08/1381), by the Ministry of Education, Youth and Sports of the Czech Republic (nos. 1M0538 and LC554) and by the Academy of Sciences of the Czech Republic (no. AVOZ50390512).

1. Deiters O. Untersuchungen über Gehirn und Rückenmark des Menschen und der Säugethiere. Braunschweig: Vieweg, 1865.

2. Lenhossek Mv. Der feinere Bau des Nervensystems im Lichte neuester Forschung. Fischer's Medicinische Buchhandlung H Kornfield: Berlin, 1893.

3. Kettenmann $\mathrm{H}$, Ransom BR. The concept of neuroglia: a historical perspective. In: Kettenmann H, Ransom BR (eds). Neuroglia. OUP: Oxford, 2005, pp 1-16.

4. Verkhratsky A. Patching the glia reveals the functional organisation of the brain. Pflugers Arch 2006; 453: 411-420.

5. Verkhratsky A, Butt A. Glial Neurobiology A text book. John Wiley \& Sons: Chichester, 2007.

6. Giaume C, Kirchhoff F, Matute C, Reichenbach A, Verkhratsky A. Glia: the fulcrum of brain diseases. Cell Death Differ 2007; 14: 1324-1335.

7. Porter JT, McCarthy KD. Astrocytic neurotransmitter receptors in situ and in vivo. Prog Neurobiol 1997; 51: 439-455.

8. Verkhratsky A, Steinhauser C. Ion channels in glial cells. Brain Res Brain Res Rev 2000; 32: $380-412$.

9. Verkhratsky A, Kirchhoff F. Glutamate-mediated neuronal-glial transmission. J Anat 2007; 210: $651-660$

10. Verkhratsky A. Calcium ions and integration in neural circuits. Acta Physiol (Oxf) 2006; 187: 357-369.

11. Dermietzel R, Gao $\mathrm{Y}$, Scemes E, Vieira D, Urban M, Kremer $M$ et al. Connexin43 null mice reveal that astrocytes express multiple connexins. Brain Res Brain Res Rev 2000; 32: 45-56.

12. Giaume $\mathrm{C}, \mathrm{McC}$ arthy $\mathrm{KD}$. Control of gap-junctional communication in astrocytic networks. Trends Neurosci 1996; 19: 319-325.

13. Volterra A, Meldolesi J. Astrocytes, from brain glue to communication elements: the revolution continues. Nat Rev Neurosci 2005; 6: 626-640.

14. Nedergaard M, Ransom B, Goldman SA. New roles for astrocytes: redefining the functional architecture of the brain. Trends Neurosci 2003; 26: 523-530.

15. Bushong EA, Martone ME, Jones YZ, Ellisman MH. Protoplasmic astrocytes in $C A 1$ stratum radiatum occupy separate anatomical domains. J Neurosci 2002; 22: 183-192.

16. Oberheim NA, Wang X, Goldman S, Nedergaard M. Astrocytic complexity distinguishes the human brain. Trends Neurosci 2006; 29: 547-553.

17. Mulligan SJ, MacVicar BA. Calcium transients in astrocyte endfeet cause cerebrovascular constrictions. Nature 2004; 431: 195-199.

18. Zonta M, Angulo MC, Gobbo S, Rosengarten B, Hossmann KA, Pozzan T et al. Neuron-toastrocyte signaling is central to the dynamic control of brain microcirculation. Nat Neurosc 2003; 6: 43-50.

19. Iadecola C, Nedergaard M. Glial regulation of the cerebral microvasculature. Nat Neurosci 2007; 10: 1369-1376

20. Houades V, Koulakoff A, Ezan P, Seif I, Giaume C. Gap junction-mediated astrocytic networks in the mouse barrel cortex. J Neurosci 2008; 28: 5207-5217.

21. Scemes E, Giaume C. Astrocyte calcium waves: what they are and what they do. Glia 2006; 54: 716-725

22. Kang J, Kang N, Lovatt D, Torres A, Zhao Z, Lin J et al. Connexin 43 hemichannels are permeable to ATP. J Neurosci 2008; 28: 4702-4711.

23. Tabernero A, Medina JM, Giaume C. Glucose metabolism and proliferation in glia: role of astrocytic gap junctions. J Neurochem 2006; 99: 1049-1061.

24. Cornell-Bell AH, Finkbeiner SM, Cooper MS, Smith SJ. Glutamate induces calcium waves in cultured astrocytes: long-range glial signaling. Science 1990; 247: 470-473.

25. Verkhratsky A, Orkand RK, Kettenmann H. Glial calcium: homeostasis and signaling function. Physiol Rev 1998; 78: 99-141.

26. Verkhratsky A, Toescu EC. Neuronal-glial networks as substrate for CNS integration. J Cell Mol Med 2006; 10: 826-836.
27. Nedergaard M. Direct signaling from astrocytes to neurons in cultures of mammalian brain cells. Science 1994; 263: 1768-1771.

28. Pakhotin P, Verkhratsky A. Electrical synapses between Bergmann glial cells and Purkinje neurones in rat cerebellar slices. Mol Cell Neurosci 2005; 28: 79-84.

29. Halassa MM, Fellin T, Haydon PG. The tripartite synapse: roles for gliotransmission in health and disease. Trends Mol Med 2007; 13: 54-63.

30. Araque A, Parpura V, Sanzgiri RP, Haydon PG. Tripartite synapses: glia, the unacknowledged partner. Trends Neurosci 1999; 22: 208-215.

31. Lin SC, Bergles DE. Synaptic signaling between neurons and glia. Glia 2004; 47: 290-298.

32. Jabs R, Pivneva T, Huttmann K, Wyczynski A, Nolte C, Kettenmann H et al. Synaptic transmission onto hippocampal glial cells with hGFAP promoter activity. J Cell Sci 2005; 118: 3791-3803.

33. Panickar KS, Norenberg MD. Astrocytes in cerebral ischemic injury: morphological and general considerations. Glia 2005; 50: 287-298.

34. Kofuji $P$, Newman EA. Potassium buffering in the central nervous system. Neuroscience 2004; 129: 1045-1056.

35. Danbolt NC. Glutamate uptake. Progr Neurobiol 2001; 65: 1-105.

36. Kirischuk S, Kettenmann H, Verkhratsky A. Membrane currents and cytoplasmic sodium transients generated by glutamate transport in Bergmann glial cells. Pflugers Arch 2007; 454: $245-252$.

37. Dringen R. Metabolism and functions of glutathione in brain. Prog Neurobiol 2000; 62 649-671.

38. Pekny M, Nilsson M. Astrocyte activation and reactive gliosis. Glia 2005; 50: 427-434.

39. Butt AM, Hamilton N, Hubbard P, Pugh M, Ibrahim M. Synantocytes: the fifth element. $J$ Anat 2005; 207: 695-706.

40. Pekny M, Wilhelmsson U, Bogestal YR, Pekna M. The role of astrocytes and complement system in neural plasticity. Int Rev Neurobiol 2007; 82: 95-111.

41. Broe M, Kril J, Halliday GM. Astrocytic degeneration relates to the severity of disease in frontotemporal dementia. Brain 2004; 127: 2214-2220.

42. Kersaitis C, Halliday GM, Kril JJ. Regional and cellular pathology in frontotempora dementia: relationship to stage of disease in cases with and without Pick bodies. Acta Neuropathol 2004; 108: 515-523.

43. Potts R, Leech RW. Thalamic dementia: an example of primary astroglial dystrophy of Seitelberger. Clin Neuropathol 2005; 24: 271-275.

44. Vanzani MC, lacono RF, Caccuri RL, Troncoso AR, Berria Ml. Regiona differences in astrocyte activation in HIV-associated dementia. Medicina (B Aires) 2006; 66: $108-112$

45. Deshpande M, Zheng J, Borgmann K, Persidsky R, Wu L, Schellpeper C et al. Role of activated astrocytes in neuronal damage: potential links to HIV-1-associated dementia. Neurotox Res 2005; 7: 183-192.

46. Nardacci R, Antinori A, Kroemer G, Piacentini M. Cell death mechanisms in HIV-associated dementia: the involvement of syncytia. Cell Death Differ 2005; 12 (Suppl 1): 855-858.

47. Thompson KA, McArthur JC, Wesselingh SL. Correlation between neurological progression and astrocyte apoptosis in HIV-associated dementia. Ann Neurol 2001; 49: $745-752$

48. Alzheimer A. ber eine eigenartige Erkrankung der Hirnrinde. Allg Z Psychiat Psych-Gerich Med 1907; 64: 146-148.

49. Thompson PM, Hayashi KM, Dutton RA, Chiang MC, Leow AD, Sowell ER et al. Tracking Alzheimer's disease. Ann N Y Acad Sci 2007; 1097: 183-214.

50. Thompson PM, Hayashi KM, de Zubicaray G, Janke AL, Rose SE, Semple J et al. Dynamics of gray matter loss in Alzheimer's disease. J Neurosci 2003; 23: 994-1005.

51. Alzheimer A. Beiträge zur Kenntnis der pathologischen Neuroglia und ihrer Beziehungen zu den Abbauvorgängen im Nervengewebe. In: Nissl F, Alzheimer A (eds). Histologische und histopathologische Arbeiten über die Grosshirnrinde mit besonderer Berücksichtigung der pathologischen Anatomie der Geisteskrankheiten. Gustav Fischer: Jena, 1910, pp 401-562.

52. DeWitt DA, Perry G, Cohen M, Doller C, Silver J. Astrocytes regulate microglial phagocytosis of senile plaque cores of Alzheimer's disease. Exp Neurol 1998; 149 329-340.

53. Abramov AY, Canevari L, Duchen MR. Changes in intracellular calcium and glutathione in astrocytes as the primary mechanism of amyloid neurotoxicity. J Neurosci 2003; 23 5088-5095.

54. Nagele RG, Wegiel J, Venkataraman V, Imaki H, Wang KC. Contribution of glial cells to the development of amyloid plaques in Alzheimer's disease. Neurobiol Aging 2004; 25 663-674.

55. Nagele RG, D'Andrea MR, Lee H, Venkataraman V, Wang HY. Astrocytes accumulate A beta 42 and give rise to astrocytic amyloid plaques in Alzheimer disease brains. Brain Res 2003: 971: 197-209.

56. Toledano A, Alvarez Ml. Lesions and dysfunctions of the nucleus basalis as Alzheimer's disease models: general and critical overview and analysis of the long-term changes in several excitotoxic models. Curr Alzheimer Res 2004; 189: 214

57. Cassel JC, Mathis C, Majchrzak M, Moreau PH, Dalrymple-Alford JC. Coexisting cholinergic and parahippocampal degeneration: a key to memory loss in dementia and a challenge for transgenic models? Neurodegener Dis 2008; 5: 304-317.

58. Gotz J, Streffer JR, David D, Schild A, Hoerndli F, Pennanen $L$ et al. Transgenic animal models of Alzheimer's disease and related disorders: histopathology, behavior and therapy. Mol Psychiatry 2004; 9: 664-683. 
59. Biegon A Greenberger V Segal M. Quantitative histochemistry of brain acetylcholinesterase and learning rate in the aged rat. Neurobiol Aging 1986; 7: 215-217.

60. Bertoni-Freddari C, Giuli C, Pieri C, Paci D. Quantitative investigation of the morphological plasticity of synaptic junctions in rat dentate gyrus during aging. Brain Res 1986; 366: 187-192.

61. Sani S, Traul D, Klink A, Niaraki N, Gonzalo-Ruiz A, Wu CK et al. Distribution, progression and chemical composition of cortical amyloid-beta deposits in aged rhesus monkeys: similarities to the human. Acta Neuropathol 2003; 105: 145-156.

62. Bartus RT, Dean III RL, Beer B, Lippa AS. The cholinergic hypothesis of geriatric memory dysfunction. Science 1982; 217: 408-414.

63. Pepeu G, Marconcini Pepeu I. Dysfunction of the brain cholinergic system during aging and after lesions of the nucleus basalis of Meynert. J Neural Transm Suppl 1994; 44: 189-194.

64. Wellman CL, Pelleymounter MA. Differential effects of nucleus basalis lesions in young adult and aging rats. Neurobiol Aging 1999; 20: 381-393.

65. Wiley RG. Neural lesioning with ribosome-inactivating proteins: suicide transport and immunolesioning. Trends Neurosci 1992; 15: 285-290.

66. Games D, Adams D, Alessandrini R, Barbour R, Berthelette P, Blackwell C et Alzheimer-type neuropathology in transgenic mice overexpressing V717F beta-amyloid precursor protein. Nature 1995; 373: 523-527.

67. Hsiao K, Chapman P, Nilsen S, Eckman C, Harigaya Y, Younkin S et al. Correlative memory deficits, Abeta elevation, and amyloid plaques in transgenic mice. Science 1996; 274: 99-102.

68. Arendash GW, Lewis J, Leighty RE, McGowan E, Cracchiolo JR, Hutton M et al. Multimetric behavioral comparison of APPsw and P301L models for Alzheimer's disease: linkage of poorer cognitive performance to tau pathology in forebrain. Brain Res 2004; 1012: $29-41$.

69. Galvan V, Zhang J, Gorostiza OF, Banwait S, Huang W, Ataie M et al. Long-term prevention of Alzheimer's disease-like behavioral deficits in PDAPP mice carrying a mutation in Asp664. Behav Brain Res 2008; 191: 246-255.

70. Gruart A, Lopez-Ramos JC, Munoz MD, Delgado-Garcia JM. Aged wild-type and APP PS1, and APP+PS1 mice present similar deficits in associative learning and synaptic plasticity independent of amyloid load. Neurobiol Dis 2008; 30: 439-450.

71. Savonenko A, Xu GM, Melnikova T, Morton JL, Gonzales V, Wong MP et al. Episodic-like memory deficits in the APPswe/PS1dE9 mouse model of Alzheimer's disease: relationships to beta-amyloid deposition and neurotransmitter abnormalities. Neurobiol Dis 2005; 18: 602-617.

72. Dodart JC, Mathis C, Saura J, Bales KR, Paul SM, Ungerer A. Neuroanatomica abnormalities in behaviorally characterized APP(V717F) transgenic mice. Neurobiol Dis 2000; 7: 71-85.

73. Janus C, Pearson J, McLaurin J, Mathews PM, Jiang Y, Schmidt SD et al. A beta peptide immunization reduces behavioural impairment and plaques in a model of Alzheimer's disease. Nature 2000; 408: 979-982.

74. Schindowski K, Bretteville A, Leroy K, Begard S, Brion JP, Hamdane M et al. Alzheimer's disease-like tau neuropathology leads to memory deficits and loss of functional synapses in a novel mutated tau transgenic mouse without any motor deficits. Am J Pathol 2006; 169 599-616.
75. Oddo S, Caccamo A, Shepherd JD, Murphy MP, Golde TE, Kayed R et al. Triple-transgenic model of Alzheimer's disease with plaques and tangles: intracellular Abeta and synaptic dysfunction. Neuron 2003; 39: 409-421.

76. Brendza RP, Bales KR, Paul SM, Holtzman DM. Role of apoE/Abeta interactions in Alzheimer's disease: insights from transgenic mouse models. Mol Psychiatry 2002; 7: 132-135.

77. Gotz J, Probst A, Spillantini MG, Schafer T, Jakes R, Burki $K$ et al. Somatodendritic localization and hyperphosphorylation of tau protein in transgenic mice expressing the longest human brain tau isoform. EMBO J 1995; 14: 1304-1313.

78. Lewis J, McGowan E, Rockwood J, Melrose H, Nacharaju P, Van Slegtenhorst M et al. Neurofibrillary tangles, amyotrophy and progressive motor disturbance in mice expressing mutant (P301L) tau protein. Nat Genet 2000; 25: 402-405.

79. Oddo S, Caccamo A, Kitazawa M, Tseng BP, LaFerla FM. Amyloid deposition precedes tangle formation in a triple transgenic model of Alzheimer's disease. Neurobiol Aging 2003; 24: 1063-1070.

80. McKee AC, Carreras I, Hossain L, Ryu H, Klein WL, Oddo S et al. Ibuprofen reduces Abeta, hyperphosphorylated tau and memory deficits in Alzheimer mice. Brain Res 2008; 1207: 225-236.

81. Carroll JC, Rosario ER, Chang L, Stanczyk FZ, Oddo S, LaFerla FM et al. Progesterone and estrogen regulate Alzheimer-like neuropathology in female 3xTg-AD mice. J Neurosci 2007; 27: 13357-13365.

82. Rodriguez JJ, Mackie K, Pickel VM. Ultrastructural localization of the CB1 cannabinoid receptor in mu-opioid receptor patches of the rat Caudate putamen nucleus. J Neurosci 2001; 21: 823-833

83. Chvatal A, Anderova M, Kirchhoff F. Three-dimensional confocal morphometry - a new approach for studying dynamic changes in cell morphology in brain slices. J Anat 2007; 210: $671-683$

84. Chvatal A, Anderova M, Hock M, Prajerova I, Neprasova H, Chvatal V et al. Threedimensional confocal morphometry reveals structural changes in astrocyte morphology in situ. J Neurosci Res 2007; 85: 260-271.

85. Senitz D, Reichenbach A, Smith Jr TG. Surface complexity of human neocortical astrocytic cells: changes with development, aging, and dementia. J Hirnforsch 1995; 36: 531-537.

86. Léveillé F, Ortega JB, Rodríguez JJ, Meadows RS, Verkhratsky A, Nicole O et al. Increase in excitatory synapses density and functional modification of NMDA receptors-mediated responses induced by $\beta$-amyloid oligomers. Unpublished observations.

87. Rodríguez JJ, Jones VC, Tabuchi M, Allan SM, Knight EM, LaFerla FM et al. Impaired adult neurogenesis in the dentate gyrus of a triple transgenic mouse model of Alzheimer's disease. PLOS One 2008; 3: e2935.

88. Tian GF, Azmi H, Takano T, Xu Q, Peng W, Lin J et al. An astrocytic basis of epilepsy. Nat Med 2005; 11: 973-981.

89. Nedergaard M, Dirnagl U. Role of glial cells in cerebral ischemia. Glia 2005; 50: 281-286.

90. Scheff SW, Price DA, Schmitt FA, DeKosky ST, Mufson EJ. Synaptic alterations in CA1 in mild Alzheimer disease and mild cognitive impairment. Neurology 2007; 68: 1501-1508.

91. Terry RD. Cell death or synaptic loss in Alzheimer disease. J Neuropathol Exp Neurol 2000; 59: 1118-1119. 